\title{
EUS guided fine needle injection is superior to direct endoscopic injection of 2-octyl cyanoacrylate for the treatment of gastric variceal bleeding
}

\author{
Benjamin L. Bick, MD, Mohammad Al-Haddad, MD, Suthat Liangpunsakul, MD, Marwan S. Ghabril, \\ MD, John M. DeWitt MD, FACG, FASGE, AGAF
}

Division of Gastroenterology \& Hepatology, Indiana University, Indianapolis, Indiana, USA

\author{
Funding: None
}

\author{
Corresponding Author \\ John DeWitt MD, FACG, FACP, FASGE, AGAF \\ Professor of Medicine \\ Division of Gastroenterology \& Hepatology \\ Indiana University Health Medical Center \\ 550 N. University Blvd., UH 4100 \\ Indianapolis, IN 46202 \\ Phone: 317-944-1113
}

Fax: 317-948-8144

Email: jodewitt@iupui.edu

Running head: EUS guided injection of gastric varices

This is the author's manuscript of the article published in final edited form as:

Bick, B. L., Al-Haddad, M., Liangpunsakul, S., Ghabril, M. S., \& DeWitt, J. M. (2018). EUS-guided fine needle injection is superior to direct endoscopic injection of 2-octyl cyanoacrylate for the treatment of gastric variceal bleeding. Surgical Endoscopy. https://doi.org/10.1007/s00464-018-6462-z 


\begin{abstract}
Background

Endoscopic injection of cyanoacrylate into gastric varices may be performed by EUSguided fine needle injection (EUS-FNI) or direct endoscopic injection (DEI). The aim of this study is to compare the rate of recurrent GV bleeding and adverse events between DEI and EUS-FNI for treatment of GV.
\end{abstract}

\title{
Methods
}

In a single center study, a retrospective cohort of patients with actively/recently bleeding or high-risk GV treated with DEI were compared with a prospective cohort of similar patients treated with EUS-FNI. Repeat endoscopy after index treatment was performed 3 months later or earlier if rebleeding occurred. The main outcomes assessed were rates of GV or overall rebleeding and adverse events.

\section{Results}

Forty patients (mean age $57.2 \pm 9.1$ years, $73 \%$ male) and 64 patients (mean age $58.0 \pm 12.5$ years, $52 \%$ male) underwent DEI and EUS-FNI, respectively. Compared to the DEI group, the frequency of isolated gastric varices type $1(\mathrm{IGV} 1)$ were higher $(\mathrm{p}<0.001)$ but MELD scores were lower $(\mathrm{p}=0.004)$ in the EUS-FNI group. At index endoscopy, EUS-FNI utilized a lower mean volume of cyanoacrylate $(2.0 \pm 0.8 \mathrm{~mL}$ vs $3.3 \pm 1.3 \mathrm{~mL} ; \mathrm{p}<0.001)$ and injected a greater number of varices $(1.6 \pm 0.7 \mathrm{vs} 1.1 \pm 0.4$ $\mathrm{p}<0.001)$ compared to DEI. Overall GV rebleeding (5/57 [8.8\%] vs $9 / 38$ [23.7\%]; $\mathrm{p}=0.045)$ and non-GV related gastrointestinal bleeding $(7 / 64[10.9 \%]$ vs $11 / 40$ [27.5\%]; $p=0.030)$ was less frequent in the EUS- 
FNI group compared to the DEI group, respectively. Adverse event rates were similar $(20.3 \%$ vs. $17.5 \%$, $\mathrm{p}=0.723)$.

\section{Conclusions}

EUS-guided CYA injection of active or recently bleeding GV in patients with portal hypertension appears to decrease the rate of GV rebleeding despite injection of more varices and less CYA volume during the initial endoscopic procedure. Adverse events are similar between the two groups. EUS-FNI appears to be the preferred strategy for treatment of these patients.

Key words: endoscopic ultrasound, gastric varices, cyanoacrylate, fine needle injection, variceal bleeding 


\section{INTRODUCTION}

Gastric varices (GV) are collateral vessels that arise from portal hypertension, which in turn leads to reversal of blood flow from the splenic vein into the left renal vein.[1] GV are found in $20 \%$ of patients with cirrhosis and can bleed in 44-65\% of patients within five years.[2-4] Although less prevalent than esophageal varices, bleeding from $\mathrm{GV}$ is more severe[3,5] and is associated with a one-year mortality rate of over $50 \%$. Effective treatment is therefore paramount.

Past endoscopic treatment for GV involved direct intra-variceal injection of sclerosants such as sodium tetradecyl sulfate to achieve hemostasis and GV eradication. However, the rate of treatment success was suboptimal with hemostasis achieved in only about two-thirds of the patients and rebleeding occurring in 23-89\%.[6,5] Since the first report of its use in 1986[7], two forms of cyanoacrylate, Nbutyl-2 cyanoacrylate followed by 2-octyl cyanoacrylate, have been successfully utilized for endoscopic treatment of GV with greater treatment success.[8-16] However, cyanoacrylate injection of GV has been associated with rare but significant adverse events, such as glue embolization resulting in pulmonary embolism[17-19], cerebrovascular events, infection/bacteremia[20,21], splenic infarction[22,23], and portal/splenic vein thrombosis[24,25].

The technique of endoscopic treatment of GV was later refined with the use of EUSguidance[26,27,18,28,29] to theoretically direct injection of GV more accurately, minimize the volume of cyanoacrylate injected, target the perforating vein when possible and confirm GV eradication using Doppler examination[4]. Despite the theoretical advantages of EUS-guided fine needle injection (EUSFNI) of cyanoacrylate over direct endoscopic injection (DEI) in the treatment of GV, currently no comparative studies exist between the two techniques. The aim of this study was therefore to compare the rate of recurrent GV bleeding and adverse event rates between DEI and EUS-FNI for treatment of GV. 


\section{MATERIALS AND METHODS}

\section{Study design and participants}

A two-part observational, comparative study was conducted comprising consecutive patients over 18 years of age who underwent endoscopic treatment of gastric varices at Indiana University Health Medical Center from November 2006 to November 2017. Patients were considered for endoscopic injection of gastric varices for: 1) active or recent bleeding (within 4 weeks) from GV or; 2) primary prophylaxis for high-risk non-bleeding GV. Furthermore, all patients were unable or unwilling to undergo alternative therapies for GV (such as transjugular intrahepatic portosystemic shunts (TIPS) or surgery), or were advised by their referring provider to undergo endoscopic therapy. Patients were excluded if unable to undergo conscious sedation or general anesthesia, had an irreversible coagulopathy or bleeding risk (platelet count $<50,000$ or INR $>1.5$ ) or were $<18$ years of age. Current or former use of non-selective beta-blockers was not considered a contraindication for therapy.

The first part of the study was a retrospective review of patients with gastric varices, who underwent injection of 2-octyl cyanoacrylate (CYA) (Dermabond; Johnson \& Johnson, New Brunswick, New Jersey) under direct endoscopic visualization from 2006 to 2011. The results of this retrospective review have been previously published[10]. However from 2012 onwards, at our institution, the practice of DEI was replaced by utilization of EUS-guidance for injection of CYA into GV in all patients. These patients were enrolled in a prospectively maintained database (the second part of the study), which was utilized to compare outcomes with the DEI cohort (NCT02037659). The study was approved by the Institutional Review Board at our institution and written informed consent for the procedure was obtained from all patients.

\section{Procedural technique}

All procedures were performed under deep sedation or general anesthesia in the left lateral position. DEI was performed by one of three experienced endoscopists and EUS-FNI was performed by two endosonographers (Figure 1). Intravenous ampicillin/sulbactam, ceftriaxone or a fluoroquinolone 
were administered to all patients prior to the endoscopic procedure to minimize the risk of secondary bacterial infection. Oral or intravenous antibiotics were continued for at least three days following variceal injection.

\section{Direct endoscopic injection (DEI)}

A detailed description of the procedural technique is provided in our previously published report[10]. To summarize, an endoscopic examination was first performed using a standard or therapeutic gastroscope (GIF-160, GIF-180, GIF-1TH, Olympus America Inc., Center Valley, Pennsylvania) in order to visualize the GV in the retroflexed position. Once identified, the GV was observed to identify active bleeding, stigmata of recent bleeding, long axis diameter and Sarin classification[30]. The site and number of injections performed in each session was left to the discretion of the endoscopist; however, usually the largest GV or GV with active bleeding or stigmata of recent bleeding was targeted. A 23gauge sclerotherapy needle (Marcon-Haber MH-1-240, Cook Medical Inc., Bloomington, Indiana) primed with water was utilized to puncture the varix. About $0.25-0.5 \mathrm{~mL}$ of water was then injected into the varix to ensure correct needle placement. Once this was confirmed, a single 0.5-1.0 mL aliquot of CYA was injected into the GV under endoscopic visualization and flushed over 30-45 seconds with an additional $1 \mathrm{cc}$ of water as the needle was withdrawn. Additional sites were treated as needed or until the variceal complex appeared hardened by catheter palpation and/or bleeding had ceased.

\section{EUS-guided fine needle injection (EUS-FNI):}

A direct endoscopic examination was first performed to locate the GV and identify active bleeding, stigmata of recent bleeding and Sarin classification[30]. The GV were then identified using a linear array echoendoscope (GFUC140P, Olympus America Inc., Center Valley, Pennsylvania) by one of two methods: a) the splenic vein or posterior border of the pancreas was traced proximally towards the splenic hilum or; b) the endoscope was torqued counterclockwise just distal to the gastroesophageal junction and the tip was deflected up to retroflex in the fundus. Occasionally $60-180 \mathrm{~mL}$ of water was 
instilled into the fundus of the stomach to aid visualization of the varices. The width of the largest GV was measured. A 19-gauge or 22-gauge needle (EchoTip Ultra, Cook Medical Inc., Winston-Salem, NC or Expect, Boston Scientific Corp., Natick, Massachusetts) primed with water or saline was utilized to puncture the largest varix via the transgastric route. After aspiration of blood, the needle was flushed with $1 \mathrm{~mL}$ of water to clear the catheter. An aliquot of $0.5-1.0 \mathrm{~mL}$ of CYA was injected into the needle and then flushed with water slowly over 30-45 seconds under real-time EUS guidance until CYA solidification was complete. Repeat injection was performed until minimal to absent Doppler flow was present in the variceal complex. A perforator vein identified entering the gastric wall was sometimes targeted with the injection if Doppler suggested blood flow entering the gastric walls. Intravascular coils were utilized in a few selected patients towards the end of the prospective portion of the study.

\section{Follow-up after Endoscopy}

Endoscopic examination and/or Doppler EUS were repeated in all patients at three months postindex procedure (or sooner with recurrent bleeding) to confirm eradication. GV were considered to be eradicated by direct endoscopy when not visible and/or were hardened to catheter palpation. Eradication by Doppler EUS was considered visualization of clot and absence of flow within the gastric wall. Repeat injection was performed in the absence of eradication. After eradication and in the absence of bleeding, repeat endoscopy was performed at least annually.

\section{Outcome measures}

The primary outcome measures were the incidence of rebleeding from GV and adverse events following endoscopic therapy. The secondary outcome measure was the incidence of gastrointestinal bleeding from any cause following endoscopic therapy of GV.

Rebleeding from GV was defined as: 1) presentation with symptoms and/or signs of gastrointestinal bleeding, 2) evidence of active GV bleeding or stigmata of recent GV bleeding, and 3) no other etiology of bleeding identified. Patients undergoing therapy for primary prophylaxis were not 
included for calculation of rebleeding rates. Adverse events were defined according to a previously defined consensus[31].

\section{Data collection and follow-up}

Information on patient demographics, etiology of $\mathrm{GV}$, indication for endoscopic therapy, GV features, procedure details and outcome measures were collected, retrospectively for the DEI cohort and prospectively for the EUS-FNI cohort. Information on treatment outcomes in both groups were collected until the last known follow-up, liver transplantation or death[10].

\section{Statistical analysis}

Patient and GV characteristics, procedure details and procedural outcomes were summarized as frequencies and proportions for categorical variables and means with standard deviation and medians with interquartile ranges for continuous variables. Categorical variables were then compared between the DEI and EUS-FNI groups using either Fisher's exact test or chi-square test as indicated and continuous variables were compared using the Wilcoxon rank sum test. Statistical significance was established as $\mathrm{p}<0.05$. All datasets were compiled using Microsoft Excel (Microsoft Corporation, Redmond, Washington) and analyzed using SPSS 21 (IBM, Armonk, NY).

\section{RESULTS}

\section{Patient and GV characteristics}

Between November 2006 and April 2012, 40 consecutive patients (mean age $57.2 \pm 9.1$ years, $72.5 \%$ male) underwent DEI for eradication of gastric varices. The etiology of gastric varices was noncirrhotic portal hypertension in two (portal vein thrombosis in one and superior mesenteric vein thrombosis in one) and cirrhosis in 38 patients (95\%), with mean MELD scores of $17.2 \pm 7.8$. The most common etiology of cirrhosis was non-alcoholic steatohepatitis (NASH)/cryptogenic in 14, followed by alcohol in 8 , hepatitis $\mathrm{C}$ with alcohol in 7, and hepatitis $\mathrm{C}$ in 5 patients. The most common type of GV 
encountered was gastroesophageal varices type 2 (GOV2) (77.5\%) and the majority (95\%) of patients had either active $(n=5)$ or recent $G V$ bleeding $(n=33)$. Two were treated for primary prophylaxis. The mean size of the largest GV was $12.6 \pm 5.9 \mathrm{~mm}$ (Table 1).

Between January 2013 and November 2017, 64 consecutive patients (mean age $58.0 \pm 12.5$ years, 51.6\% male) underwent EUS-FNI for GV eradication, including 57 patients (89.1\%) with either active $(n=1)$ or recent $\mathrm{GV}$ bleeding $(n=56)$ and $7(10.9 \%)$ treated for primary prophylaxis. The etiology of GV was cirrhosis in the majority of patients ( $\mathrm{n}=54[84.4 \%]$ ), most commonly due to NASH/cryptogenic in 18 , followed by hepatitis $\mathrm{C}$ in 10 , alcohol in 10 and a combination of hepatitis $\mathrm{C} /$ alcohol in 8 patients. In the 10 patients with GV resulting from non-cirrhotic portal hypertension, the etiology was portal vein thrombosis in 5, splenic vasculature abnormality in 1 , neuroendocrine tumor of the pancreas in 1 , chronic pancreatitis in 1, cardiogenic portal hypertension in 1, and idiopathic in 1 patient. GOV2 was found in 32 $(50 \%)$ patients, followed by isolated gastric varices type 1 (IGV1) in $30(43.6 \%)$ and gastroesophageal varices type 1 (GOV1) in $2(3.1 \%)$. The mean GV size was $11.1 \mathrm{~mm} \pm 6.0$ (Table 1$)$.

Median overall follow-up for both groups was 340 days (range: 30-3336). Median follow up for the DEI and EUS-FNI group were 489 days (150-3336) and 197 days EUS-FNI (30-1107), respectively. There was no significant difference between the DEI and EUS-FNI groups for patient demographics, etiology of GV, etiology of cirrhosis, and reason for GV therapy. However, a significantly higher proportion of IGV1 were seen in the EUS-FNI group (46.9 vs. $7.5 \%$, p<0.001) and MELD scores were higher in the DEI group $(\mathrm{p}=0.004)$ (Table 1$)$.

\section{Procedural details}

During the index endoscopy, a greater mean volume of CYA was injected in the DEI group (3.3 \pm $1.3 \mathrm{mLs})$ compared to the EUS-FNI group $(2.0 \pm 0.8 \mathrm{mLs} ; \mathrm{p}<0.001)$, and a greater number of varices were injected in the EUS-FNI group $(1.6 \pm 0.7)$ compared to the DEI group $(1.1 \pm 0.4 ; \mathrm{p}<0.001)$. However there was no significant difference in the number of treatment sessions needed to eradicate GV between the DEI and EUS-FNI groups. Eradication was achieved during the index session (as confirmed 
by first follow-up endoscopy) in 30/40 (75\%) in the DEI group compared to 49/64 (79.0\%) in the EUSFNI group $(p=0.188)$.

\section{Outcome measures}

\section{Rebleeding}

DEI patients treated for active or recent GV bleeding had post-procedure GV rebleeding in 9/38 (23.7\%). In 7 of these patients, rebleeding occurred within 30 days of treatment, and rebleeding occurred after 30 days in 2 patients. Non-GV related gastrointestinal bleeding after DEI therapy occurred in 11/40 patients $(27.5 \%)$ including from esophageal varices in two, gastric antral vascular ectasia (GAVE) in one, gastric ulcer in one, portal hypertensive gastropathy (PHG) in two, arteriovenous malformation (AVM) in two and was unknown in three patients.

In the EUS-FNI group, rebleeding from GV occurred in 5/57 patients $(8.8 \%)$ who underwent therapy for either active or recent GV bleeding. Rebleeding occurred within 30 days of therapy in three patients, all of whom died from the recurrent bleeding. In one patient, rebleeding from GV occurred 389 days after the index EUS-FNI and was treated successfully with balloon-occluded retrograde transvenous obliteration (BRTO) of gastric varices. In all patients treated with EUS-FNI, non-GV related gastrointestinal bleeding after EUS-FNI occurred in 7/64 patients (10.9\%) including from PHG in one, a gastrojejunal anastomotic ulcer in one, esophageal varices in one, esophageal ulcers after variceal banding in one and was unknown in three patients.

Compared to DEI, EUS-FNI had significantly lower rates of GV rebleeding overall $(\mathrm{p}=0.045)$ and at 30 days $(\mathrm{p}=0.041)$. EUS-FNI also had lower rates of all-cause bleeding after therapy overall $(\mathrm{p}<0.001)$, at 30 days $(p=0.032)$ and between one and 6 months $(p=0.002)$. Non-GV related gastrointestinal bleeding was lower in the EUS-FNI group ( $\mathrm{p}=0.030$ ) (Table 2). On subgroup analysis, there was no significant difference in GV rebleeding rates between the DEI (8/36 [22.2\%]) and EUS-FNI (5/47 [10.6\%]) groups $(p=0.0 .150)$ in patients with cirrhosis. Subgroup analysis also did not identify differences in GV 
rebleeding rates in patients treated for secondary prophylaxis or active bleeding based on type of GV $(2 / 31[6.5 \%)$ in IGV1, $2 / 8$ [25\%] in GOV1, and 10/55 [18.2\%] in GOV2, p=0.240).

\section{Adverse events}

There was no significant difference in the overall rate of adverse events between the DEI (7/40 [17.5\%]) and EUS-FNI (13/64 [20.3\%]) groups $(\mathrm{p}=0.723)$ (Table 3). Moderate to severe adverse events were also similar $(\mathrm{p}=0.361)$ between the two groups.

Adverse events in all seven patients in the DEI group were gastrointestinal bleeding postprocedure, although none were classified as severe. In the EUS-FNI group, adverse events were observed in 13 patients. Splenic infarcts were diagnosed in two patients post-procedure. In the first patient classified as severe, splenic infarcts were diagnosed by magnetic resonance imaging (MRI) of the abdomen two days after the injection and required hospitalization for 11 days for concomitant Escherichia coli bacteremia. The second patient with a splenic infarct, classified as moderate, was hospitalized for five days and was managed conservatively. One patient presented three weeks postprocedure with chest and back pain, and was subsequently diagnosed with pulmonary embolism. The remaining nine patients had mild adverse events that were managed conservatively: abdominal pain in five, fever with/without abdominal pain in three, hypoxia post-procedure in one, and worsening encephalopathy in one patient.

On subgroup analysis, the majority of adverse events occurred in cirrhotic rather than noncirrhotic patients (19 of 20 patients with adverse events had cirrhosis). However, there was no significant difference in the adverse event rates between the DEI (7/38 [18.4\%]) and EUS-FNI (12/54 [22.2\%]) groups $(\mathrm{p}=0.718)$ in patients with cirrhosis.

\section{DISCUSSION}

In the current study, we found that the use of EUS-FNI for treatment of active or recently bleeding GV decreases the rate of post-treatment GV rebleeding compared with direct endoscopy (DEI), 
without significant differences in adverse events. However, there were several important baseline differences in these two groups. First, the predominant type of GV was different between the two groups. These differences are likely due to the fact that the endosonographers typically did not consider trace esophageal varices significant, so a higher proportion of IGV1 were documented in the EUS-FNI group. Subgroup analysis did not demonstrate that type of GV was associated with risk of GV rebleeding. Second, a higher MELD score was observed in the DEI group, but a higher MELD also did not predict risk of GV rebleeding on subgroup analysis. The lower MELD score in the EUS-FNI group likely reflects the success of the technique over time resulting in treatment of healthier patients rather than referring for transjugular portosystemic shunts (TIPS). Third, duration of follow-up was longer in the DEI group compared to the EUS-FNI group, but bleeding at greater than 6 months was not different between the two groups. The differences in duration of follow-up are due to DEI being offered at an earlier point in time. In 1986, Soehendra and colleagues[7] revolutionized the endoscopic therapy of GV with their report on successful hemostasis following intravariceal injection of N-butyl-2 cyanoacrylate (Histoacryl) in three patients presenting with active variceal bleeding. Publication of larger studies that followed confirmed these findings with hemostasis rates of $77.5-100 \%$, GV rebleeding rates of $4-23.3 \%$ and adverse event rates of $0-16 \%$ for DEI.[8-10,13-15] Moreover, DEI using cyanoacrylate has been shown to be superior to beta blockers[32] and band ligation[33,16]. DEI is also associated with lower adverse events[12] and is more cost-effective than TIPS[11]. In one study, the use of a systematic protocol for Nbutyl-2-cyanoacrylate injection in 131 patients with GV was associated with high treatment success that resulted in cessation of bleeding in all patients, with GV rebleeding rate of $6.9 \%$ and no adverse events[14]. In our study, the rate of GV rebleeding with DEI was relatively high at $23.7 \%$, with most (8/9) occurring within the first 30 days after treatment. Furthermore, our adverse event with DEI was relatively high at $17.5 \%$, all of which were related to post-procedure GI bleeding. These higher rates of rebleeding and adverse events explain the transition at our institution to the use of EUS-FNI in these patients in an attempt to decrease these event rates. 
The use of EUS-guidance in the treatment of GV has become increasingly popular since the first report of its use by Romero-Castro et al. in 2007.[28] In this pilot study of five patients, the perforator vein was successfully targeted in all patients and resulted in treatment success rate of $100 \%$, with no GV rebleeding and no adverse events. The proposed advantages of using EUS-guidance include accurate targeting of GV, identification and eradication of the perforator vessel, and confirmation of GV eradication post-procedure with Doppler examination. In our study, the rate of rebleeding was lower with EUS-FNI compared to DEI, despite using a smaller volume of CYA and injecting a larger number of varices. These data are likely explained by the targeted injection of CYA by EUS-FNI which permits realtime confirmation of both intravascular variceal injection and of clot formation during treatment compared to the more arbitrary injection by DEI. These advantages of EUS-FNI may also theoretically lower the risk of adverse events such as glue embolization yet the rate of adverse events were similar between the groups. However, our study may have been underpowered to detect any differences in adverse events. Interestingly, certain adverse events including splenic infarcts, bacteremia and pulmonary embolism were observed only in patients who underwent EUS-FNI. Observed differences in adverse events (particularly minor events) are likely explained by the difference in data collection between the EUS group (prospective) and DEI group (retrospective).

EUS-guided vascular therapy also permits insertion of coils. This was first reported by Levy et al.[34] for treatment of bleeding choledochojejunal anastomotic varices and Romero-Castro et al.[35] for treatment of gastric varices. In a small retrospective study comprising 30 patients with GV undergoing EUS-FNI of N-butyl-2 cyanoacrylate, patients receiving coil insertion had a similar rate of GV eradication (90.9\% for coil vs. $94.7 \%$ for cyanoacrylate) but a significantly lower incidence of adverse events (9.1 vs. $57.9 \%, \mathrm{p}<0.01)$.[18] Furthermore, when cyanoacrylate was used in combination with coils for GV treatment in a large retrospective study of 152 patients with a mean follow-up period of 436 days, GV eradication was seen in $93 \%$, rebleeding in 3\%, and adverse events in $7 \%$ (including pulmonary embolism in one patient).[36] The current and previous studies with 10 or more patients utilizing EUSFNI for treatment of gastric varices are included in Table 4.[36-38,26,18] The rate of variceal rebleeding 
in these studies is $5-29 \%$ with an adverse event rates of $7.1-40 \%$. The adverse event rate is higher in our study likely because of both the prospective data collection and precautionary hospitalization of some patients with post procedural abdominal pain.

There are several limitations to our study. First, this is not a randomized trial but a comparative study utilizing retrospective database for DEI group and prospectively collected data from the EUS-FNI group over two separate periods of time. Second, sample sizes are small for both groups, and there is a possibility that the study was not adequately powered to detect a significant difference in adverse events between the two groups. Third, all procedures were performed at a tertiary referral center by experienced endoscopists and therefore the study results may not be generalizable to all institutions.

In conclusion, EUS-guided CYA injection of active or recently bleeding GV in patients with portal hypertension appears to decrease the rate of GV rebleeding despite injection of more varices and less CYA volume during the initial endoscopic procedure. Adverse events are similar between the two groups. Thus, EUS-FNI appears to be the preferred strategy for treatment of these patients. Large prospective randomized trials comparing DEI and EUS-FNI are needed. 


\section{Figure 1 legend}

Injection of gastric varices by direct endoscopic injection or EUS guided injection. A, direct endoscopic injection of cyanoacrylate into gastric varices. B, 1 month follow up after injection demonstrating firmness of the variceal complex to forceps palpation. $\mathbf{C}$, Linear EUS Doppler flow within gastric varices. D, EUS guided fine needle injection of gastric varices. E, Post injection clot formation and resultant acoustic shadowing within gastric varices. F, 1 month follow up demonstrating decreased Doppler flow at site of injection. 
Relevant Disclosures: Drs. Bick, Al-Haddad, Liangpunsukal, Ghabril, and DeWitt have no conflicts of interest or financial ties to disclose.

\section{References}

1. Shah V, Kamath P (2016) Portal hypertension and variceal bleeding. In: Feldman M, Friedman L, Brandt L (eds) Sleisenger and Fordtran's Gastrointestinal and Liver Disease: Pathophysiology, diagnosis and management. 10 edn. Elsevier, Philadelphia, pp 1524-1552

2. Kim T, Shijo H, Kokawa H, Tokumitsu H, Kubara K, Ota K, Akiyoshi N, Iida T, Yokoyama M, Okumura M (1997) Risk factors for hemorrhage from gastric fundal varices. Hepatology 25 (2):307-312. doi:10.1053/jhep.1997.v25.pm0009021939

3. Sarin SK, Lahoti D, Saxena SP, Murthy NS, Makwana UK (1992) Prevalence, classification and natural history of gastric varices: a long-term follow-up study in 568 portal hypertension patients. Hepatology 16 (6):1343-1349

4. Weilert F, Binmoeller KF (2014) Endoscopic management of gastric variceal bleeding. Gastroenterol Clin North Am 43 (4):807-818. doi:10.1016/j.gtc.2014.08.010

5. Trudeau W, Prindiville T (1986) Endoscopic injection sclerosis in bleeding gastric varices. Gastrointest Endosc 32 (4):264-268

6. Sarin SK (1997) Long-term follow-up of gastric variceal sclerotherapy: an eleven-year experience. Gastrointest Endosc 46 (1):8-14

7. Soehendra N, Nam VC, Grimm H, Kempeneers I (1986) Endoscopic obliteration of large esophagogastric varices with bucrylate. Endoscopy 18 (1):25-26. doi:10.1055/s-2007-1013014

8. Franco MC, Gomes GF, Nakao FS, de Paulo GA, Ferrari AP, Jr., Libera ED, Jr. (2014) Efficacy and safety of endoscopic prophylactic treatment with undiluted cyanoacrylate for gastric varices. World $\mathrm{J}$ Gastrointest Endosc 6 (6):254-259. doi:10.4253/wjge.v6.i6.254

9. Huang YH, Yeh HZ, Chen GH, Chang CS, Wu CY, Poon SK, Lien HC, Yang SS (2000) Endoscopic treatment of bleeding gastric varices by N-butyl-2-cyanoacrylate (Histoacryl) injection: long-term efficacy and safety. Gastrointest Endosc 52 (2):160-167. doi:10.1067/mge.2000.104976

10. Kahloon A, Chalasani N, DeWitt J, Liangpunsakul S, Vinayek R, Vuppalanchi R, Ghabril M, Chiorean M (2014) Endoscopic therapy with 2-octyl-cyanoacrylate for the treatment of gastric varices. Dig Dis Sci 59 (9):2178-2183. doi:10.1007/s10620-014-3148-9

11. Mahadeva S, Bellamy MC, Kessel D, Davies MH, Millson CE (2003) Cost-effectiveness of N-butyl2-cyanoacrylate (histoacryl) glue injections versus transjugular intrahepatic portosystemic shunt in the management of acute gastric variceal bleeding. Am J Gastroenterol 98 (12):2688-2693.

doi:10.1111/j.1572-0241.2003.08769.x

12. Procaccini NJ, Al-Osaimi AM, Northup P, Argo C, Caldwell SH (2009) Endoscopic cyanoacrylate versus transjugular intrahepatic portosystemic shunt for gastric variceal bleeding: a single-center U.S. analysis. Gastrointest Endosc 70 (5):881-887. doi:10.1016/j.gie.2009.03.1169

13. Rengstorff DS, Binmoeller KF (2004) A pilot study of 2-octyl cyanoacrylate injection for treatment of gastric fundal varices in humans. Gastrointest Endosc 59 (4):553-558

14. Seewald S, Ang TL, Imazu H, Naga M, Omar S, Groth S, Seitz U, Zhong Y, Thonke F, Soehendra N (2008) A standardized injection technique and regimen ensures success and safety of N-butyl-2cyanoacrylate injection for the treatment of gastric fundal varices (with videos). Gastrointest Endosc 68 (3):447-454. doi:10.1016/j.gie.2008.02.050

15. Soehendra N, Grimm H, Nam VC, Berger B (1987) N-butyl-2-cyanoacrylate: a supplement to endoscopic sclerotherapy. Endoscopy 19 (6):221-224. doi:10.1055/s-2007-1018288

16. Tan PC, Hou MC, Lin HC, Liu TT, Lee FY, Chang FY, Lee SD (2006) A randomized trial of endoscopic treatment of acute gastric variceal hemorrhage: N-butyl-2-cyanoacrylate injection versus band ligation. Hepatology 43 (4):690-697. doi:10.1002/hep.21145 
17. Berry PA, Cross TJ, Orr DW (2007) Clinical challenges and images in GI. Pulmonary embolization of histoacryl "glue" causing hypoxia and cardiovascular instability. Gastroenterology 133 (5):1413, 1748. doi:10.1053/j.gastro.2007.09.051

18. Romero-Castro R, Ellrichmann M, Ortiz-Moyano C, Subtil-Inigo JC, Junquera-Florez F, Gornals JB, Repiso-Ortega A, Vila-Costas J, Marcos-Sanchez F, Munoz-Navas M, Romero-Gomez M, Brullet-Benedi E, Romero-Vazquez J, Caunedo-Alvarez A, Pellicer-Bautista F, Herrerias-Gutierrez JM, Fritscher-Ravens A (2013) EUS-guided coil versus cyanoacrylate therapy for the treatment of gastric varices: a multicenter study (with videos). Gastrointest Endosc 78 (5):711-721. doi:10.1016/j.gie.2013.05.009

19. Saracco G, Giordanino C, Roberto N, Ezio D, Luca T, Caronna S, Carucci P, De Bernardi Venon W, Barletti C, Bruno M, De Angelis C, Musso A, Repici A, Suriani R, Rizzetto M (2007) Fatal multiple systemic embolisms after injection of cyanoacrylate in bleeding gastric varices of a patient who was noncirrhotic but with idiopathic portal hypertension. Gastrointest Endosc 65 (2):345-347.

doi:10.1016/j.gie.2006.07.009

20. Wahl P, Lammer F, Conen D, Schlumpf R, Bock A (2004) Septic complications after injection of Nbutyl-2-cyanoacrylate: report of two cases and review. Gastrointest Endosc 59 (7):911-916

21. Wright G, Matull WR, Zambreanu L, O'Neill S, Smith R, O'Beirne J, Morgan MY (2009) Recurrent bacteremia due to retained embolized glue following variceal obliteration. Endoscopy 41 Suppl 2:E56-57. doi:10.1055/s-2008-1077564

22. Cheng PN, Sheu BS, Chen CY, Chang TT, Lin XZ (1998) Splenic infarction after histoacryl injection for bleeding gastric varices. Gastrointest Endosc 48 (4):426-427

23. Yu LK, Hsu CW, Tseng JH, Liu NJ, Sheen IS (2005) Splenic infarction complicated by splenic artery occlusion after N-butyl-2-cyanoacrylate injection for gastric varices: case report. Gastrointest Endosc 61 (2):343-345

24. Liu CH, Tsai FC, Liang PC, Lee CZ, Yang PM (2006) Splenic vein thrombosis and Klebsiella pneumoniae septicemia after endoscopic gastric variceal obturation therapy with N-butyl-2-cyanoacrylate. Gastrointest Endosc 63 (2):336-338. doi:10.1016/j.gie.2005.08.025

25. Shim CS, Cho YD, Kim JO, Bong HK, Kim YS, Lee JS, Lee MS, Hwang SG (1996) A case of portal and splenic vein thrombosis after Histoacryl injection therapy in gastric varices. Endoscopy 28 (5):461. doi:10.1055/s-2007-1005514

26. Gubler C, Bauerfeind P (2014) Safe and successful endoscopic initial treatment and long-term eradication of gastric varices by endoscopic ultrasound-guided Histoacryl (N-butyl-2-cyanoacrylate) injection. Scand J Gastroenterol 49 (9):1136-1142. doi:10.3109/00365521.2014.929171

27. Hikichi T, Obara K, Nakamura S, Irisawa A, Ohira H (2015) Potential application of interventional endoscopic ultrasonography for the treatment of esophageal and gastric varices. Dig Endosc $27 \mathrm{Suppl}$ 1:17-22. doi:10.1111/den.12436

28. Romero-Castro R, Pellicer-Bautista FJ, Jimenez-Saenz M, Marcos-Sanchez F, Caunedo-Alvarez A, Ortiz-Moyano C, Gomez-Parra M, Herrerias-Gutierrez JM (2007) EUS-guided injection of cyanoacrylate in perforating feeding veins in gastric varices: results in 5 cases. Gastrointest Endosc 66 (2):402-407. doi:10.1016/j.gie.2007.03.008

29. Storm AC, Kumbhari V, Saxena P, Canto MI, Azola A, Messallam AA, O'Broin-Lennon AM, Khashab MA (2014) EUS-guided angiotherapy. Gastrointest Endosc 80 (1):164-165.

doi:10.1016/j.gie.2014.04.005

30. Sarin SK, Kumar A (1989) Gastric varices: profile, classification, and management. Am J Gastroenterol 84 (10):1244-1249

31. Cotton PB, Eisen GM, Aabakken L, Baron TH, Hutter MM, Jacobson BC, Mergener K, Nemcek A, Jr., Petersen BT, Petrini JL, Pike IM, Rabeneck L, Romagnuolo J, Vargo JJ (2010) A lexicon for endoscopic adverse events: report of an ASGE workshop. Gastrointest Endosc 71 (3):446-454. doi:10.1016/j.gie.2009.10.027

32. Mishra SR, Chander Sharma B, Kumar A, Sarin SK (2010) Endoscopic cyanoacrylate injection versus beta-blocker for secondary prophylaxis of gastric variceal bleed: a randomised controlled trial. Gut 59 (6):729-735. doi:10.1136/gut.2009.192039 
33. Rio Castellanos E, Seron P, Gisbert J (2015) Endoscopic injection of cyanoacrylate glue versus other endoscopic procedures for acute bleeding gastric varices in people with portal hypertension. Cochrane Database Syst Rev 5 (Cd010180)

34. Levy MJ, Wong Kee Song LM, Kendrick ML, Misra S, Gostout CJ (2008) EUS-guided coil embolization for refractory ectopic variceal bleeding (with videos). Gastrointest Endosc 67 (3):572-574. doi:10.1016/j.gie.2007.06.063

35. Romero-Castro R, Pellicer-Bautista F, Giovannini M, Marcos-Sanchez F, Caparros-Escudero C, Jimenez-Saenz M, Gomez-Parra M, Arenzana-Seisdedos A, Leria-Yebenes V, Herrerias-Gutierrez JM (2010) Endoscopic ultrasound (EUS)-guided coil embolization therapy in gastric varices. Endoscopy 42 Suppl 2:E35-36. doi:10.1055/s-0029-1215261

36. Bhat YM, Weilert F, Fredrick RT, Kane SD, Shah JN, Hamerski CM, Binmoeller KF (2016) EUSguided treatment of gastric fundal varices with combined injection of coils and cyanoacrylate glue: a large U.S. experience over 6 years (with video). Gastrointest Endosc 83 (6):1164-1172.

doi:10.1016/j.gie.2015.09.040

37. Binmoeller KF, Weilert F, Shah JN, Kim J (2011) EUS-guided transesophageal treatment of gastric fundal varices with combined coiling and cyanoacrylate glue injection (with videos). Gastrointest Endosc 74 (5):1019-1025. doi:10.1016/j.gie.2011.06.030

38. Fujii-Lau LL, Law R, Wong Kee Song LM, Gostout CJ, Kamath PS, Levy MJ (2016) Endoscopic ultrasound (EUS)-guided coil injection therapy of esophagogastric and ectopic varices. Surg Endosc 30 (4):1396-1404. doi:10.1007/s00464-015-4342-3 